\title{
Interest of a Free Hand Camera in Wrist Arthroscopy: about 3 cases
}

\author{
Sophie Honecker ${ }^{1}$, Priscille Lazarus ${ }^{1}$, Satoshi Ichihara ${ }^{1,2}$, Sybille Facca ${ }^{1}$, Philippe \\ Liverneaux $^{1 *}$ \\ ${ }^{1}$ Department of Hand Surgery, SOS main, CCOM, University Hospital of Strasbourg, FMTS, University of Strasbourg, Icube CNRS 7357,10 avenue \\ Baumann, 67400 Illkirch \\ ${ }^{2}$ Orthopedic Surgery Department, Juntendo University, Tokyo, Japan
}

\begin{abstract}
Received: December 26, 2015; Accepted: January 27, 2016; Published: February 05, 2016
*Corresponding author: Philippe Liverneaux, Department of Hand Surgery, University Hospital of Strasbourg, 10 avenue Baumann, 67403 Illkirch F-Cedex, France, Tel: 0688894779; E-mail: Philippe.liverneaux@chru-strasbourg.fr
\end{abstract}

\begin{abstract}
The purpose of this study was to test the use of an arm guided by an infrared sensor to move the endoscopic camera in wrist arthroscopy. Three synovial cysts resections were performed arthroscopically using the "hands-free camera" technique using the Free Hand ${ }^{\circledR}$ device (OR Productivity ${ }^{\mathrm{T}}$, London, UK). In 3 cases, the advantage was to free the 2 hands of the operator. Among the disadvantages, the time of surgery was longer, the operator had to make mental images rotations to orient the camera in space, and the steric bulk of the device caused friction with the instruments in the positions extremes. Overall, our results show that if the "hands-free camera" is not used in the state in wrist arthroscopy, its adaptation would have the advantage of freeing the two hands of the operator.
\end{abstract}

Keywords: Arthroscopy; Robot; Wrist; Free hands

\section{Introduction}

Robotics is used in many surgical disciplines. In arthroscopic surgery, a single anatomical work reported an experience of using a robot at the knee to drill transosseous tunnels as part of the repair of the anterior cruciate ligament [1]. Robot-assisted arthroscopy gives the surgeon two main advantages, image stabilization, and hands-free for instrument manipulation. No clinical experience of robot-assisted wrist arthroscopy has yet been reported in the literature. The Free-Hand $₫$ device used in laparoscopic surgery to manipulate the endoscopic camera with head movements to free a hand of the operator [2,3], seems transposable in arthroscopic surgery of the wrist.

The purpose of this study was to test the use of the FreeHand $®$ device for guiding the camera in wrist arthroscopy.

\section{Material and Methods}

Three arthroscopic wrist surgeries were performed using the technique "hands-free camera." It was in the 3 cases of resection of synovial cysts, 2 dorsal scapholunate and 1 palmar. Initially, the operation was performed according to a conventional installation of wrist arthroscopy to resect synovial cysts [4]. Secondly, the procedure was performed by a robot-assisted installation of wrist arthroscopy to check the loss of synovial cysts Figure 1.

A Free Hand ${ }^{\circledR}$ device (OR Productivity ${ }^{\mathrm{TM}}$, London, UK) has been connected to an arthroscopic 2D camera $2.4 \mathrm{~mm}$. An IR radiation emitting device was placed on the operator's head. An IR receiver was placed above the monitor to the arthroscopy column. Some movements of the operator's head were programming commands. The arm guided by IR sensor (top, bottom, right, left, and zoom) for example, to move the camera to the ulnar side, the surgeon should move his head towards right meanwhile his head is being tracked by an infra-red camera that translates this movement into a lighting arrow. Once the arrow turned on towards the desired direction, the surgeon validates the action with a foot pedal. The surgeon has to push the pedal again to activate the movement and hold it as long he wants to

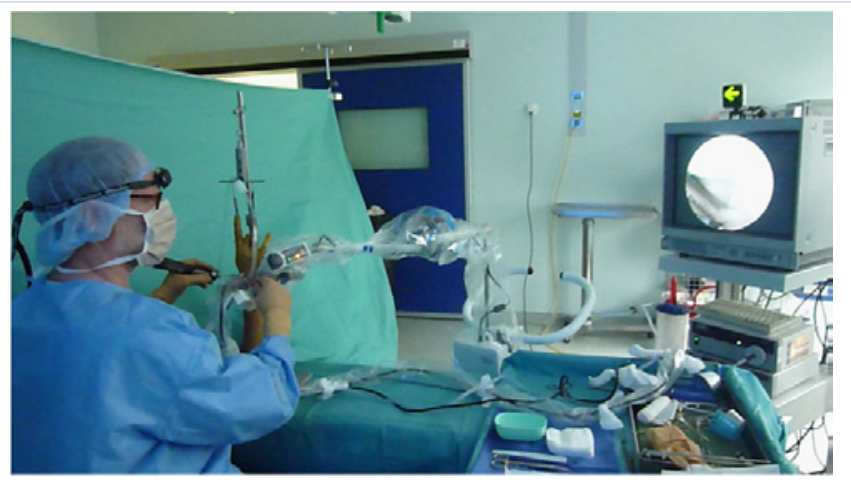

Figure 1: Installing a robot-assisted wrist arthroscopy. On the left, the operator wears on his head an infrared transmitter. To the right on the monitor is a sensitive infrared sensor to certain head movements (up, down, right, left, and zoom). Note here a programming movement to the left (arrow). In the center, the endoscopic camera is attached to a powered articulated arm. Here, the camera will move to the left when the operator has confirmed the intention of movement by pressing a pedal with a foot. 
make the movement. The camera is displaced by an articulated arm which is dressed with a sterile drape.

\section{Results}

In all 3 cases, surgical treatment of the cyst was performed successfully by conventional arthroscopy.

Quantitatively, the average total procedure time was 55 min. The average duration of the first step under conventional arthroscopy was $24 \mathrm{~min}$. The average duration of the second step in robot-assisted arthroscopy was 31 min Table 1.

Qualitatively, in the first step the operator had to use one hand to hold the optics and the other to hold an instrument. In the second step, the operator could use both hands to hold each instrument Video 1. The device allowed a stable image acquisition and an accurate and soft displacement of the optics. Because of steric hindrance, one of the operator's hands came into conflict with the Free Hand $\AA$ device Figure 2. The Free Hand $₫$ being programmed to laparoscopic surgery, an arthroscopic camera was placed on a different plane, asking the operator a rotation of mental images for correct orientation in space.

\section{Discussion}

We were able to evaluate the Free Hand $₫$ device during wrist arthroscopic surgery. The main advantages were image stabilization and hands-free for instrument manipulation.

Table 1: Duration of surgery in 3 ganglia cysts in robot-assisted arthroscopy.

\begin{tabular}{|l|l|l|l|l|}
\hline $\begin{array}{l}\text { Patient } \\
\text { (n) }\end{array}$ & $\begin{array}{l}\text { Ganglia } \\
\text { cyst }\end{array}$ & $\begin{array}{l}\text { Conventional } \\
\text { arthroscopic Time } \\
\text { (min) }\end{array}$ & $\begin{array}{l}\text { Duration robot- } \\
\text { assisted arthroscopy } \\
\text { (min) }\end{array}$ & $\begin{array}{l}\text { Total } \\
\text { Time } \\
\text { (min) }\end{array}$ \\
\hline 1 & dorsal & 17 & 35 & 52 \\
\hline 2 & dorsal & 23 & 35 & 58 \\
\hline 3 & palmar & 31 & 24 & 55 \\
\hline
\end{tabular}

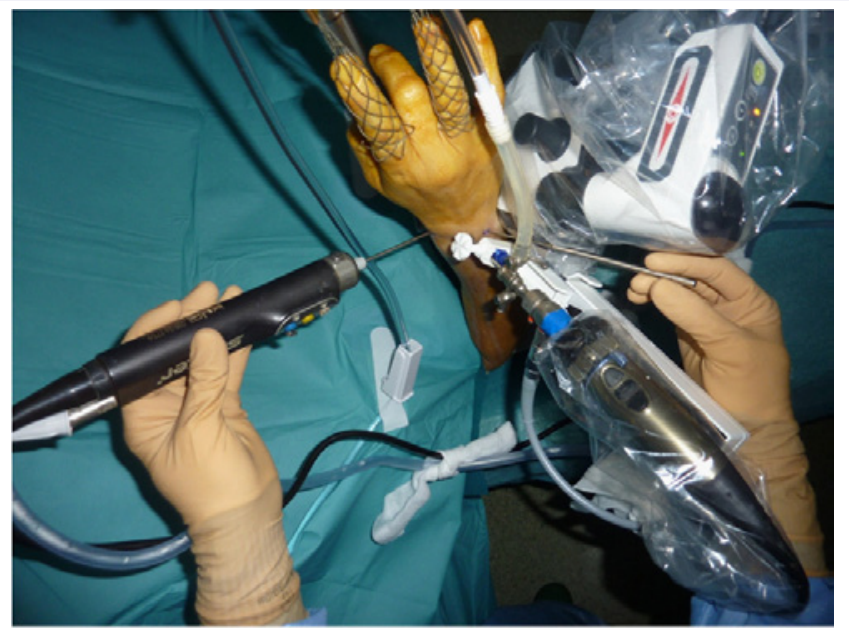

Figure 2: Close view of a robot-assisted wrist arthroscopy. The endoscopic camera maintained on a motorized swivel arm moves according to the movements of the operator's head (see Figure 1). With the "hands-free camera", the operator can use a tool in each hand.

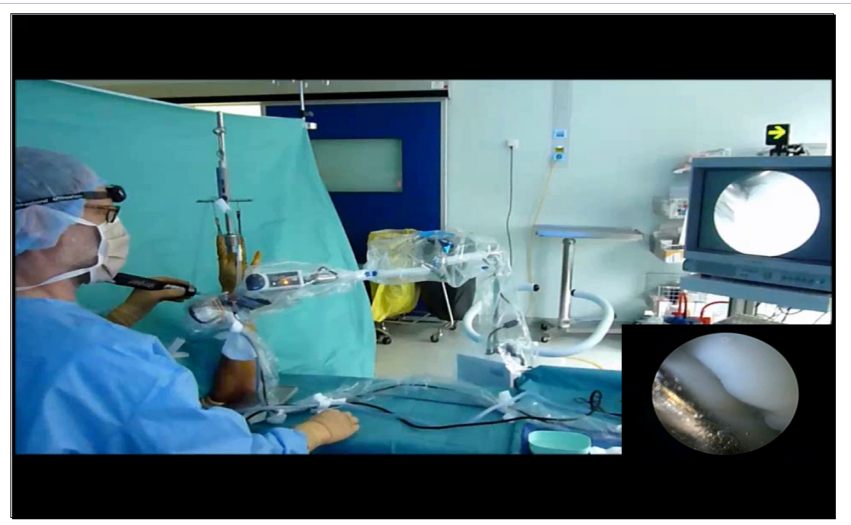

Video 1: Robot -assisted wrist arthroscopy. On the left, the operator wears on his head an infrared transmitter. To the right on the monitor is a sensitive infrared sensor to certain head movements (up, down, right, left, and zoom). In the center, the endoscopic camera is attached to a powered articulated arm.

However, the robot has not been conceived for wrist arthroscopy and needs some improvement in size and time to set up.

In orthopedic surgery, robotic surgery is used to open knee surgery or hip. The most frequently used robots are robodoc $₫$ practicing automatic bone cuts in total knee replacement [5], and a femoral version that practice automatic preparation of femoral shaft in total hip replacement [6].

In general surgery, it is used in urological endoscopy [7], digestive [8], and gynecological [9]. The most used are the da Vinci ${ }^{\circledR}$ robot and Free-Hand ${ }^{\circledR}$. The latter has an arm guided by infrared (IR) sensor to move the endoscopic camera by movements of the operator's head. The advantage of this technique "hands-free camera" is to afford to do without an operating aid, reducing the cost of the intervention.

In wrist arthroscopy, the camera is always maintained either by the hand of the operator or by an assistant. No use of robotics has yet been reported in the literature.

In our short series of robot-assisted wrist arthroscopy, the major advantage of the technique was to free the two hands of the operator, allowing easier handling 2 instruments. Among the disadvantages, the time of the intervention was increased by half an hour, probably because the operator was still in its learning curve. Another drawback was that the Free Hand ${ }^{\circledR}$ being programmed to laparoscopic surgery. An endoscopic camera was placed on a different plane, asking the operator a rotation of mental images to the correct orientation in space. Finally, the steric bulk of the device caused friction with the instruments in extreme positions.

\section{Conclusion}

Overall, a " free hand camera " in wrist arthroscopy can not be used for wrist arthroscopy without specific configuration. Improvements need to be developed to enable its use in clinical practice whose major advantage is to allow the operator to use both hands to manipulate instruments. 


\section{References}

1. Volker M, Andreas B, Richard ED, Van Scyoc A, Freddie HF, Woo SL. Accuracy of anterior cruciate ligament tunnel placement with an active robotic system: A cadaveric study. Arthroscopy. 2002;18:968973.

2. Stolzenburg, J, Franz T, Minh D, Kallidonis P, Liatsikos E, Hicks J, Nicolaus $M$, et al. Comparison of the FreeHand $₫$ robotic camera holder to human assistants during the endoscopic extraperitoneal radical prostatectomy. J.Endourology. 2011;107:970-974.

3. Brown CT, Kooiman G, Sharma DM, Poulsen J, Grange P. Scarless single-port laparoscopic pelvic kidney nephrectomy. J Laparoendosc Adv Surg Tech A. 2010;20:743-756.

4. Atzei A, Luchetti R, Sgarbossa A, Carità E, Llusà M. Installation, voies d'abord et exploration normale en arthroscopie du poignet. Chir Main. 2006;25:S131-S144.

5. Liow MH, Xia Z, Wong MK, Tay KJ, Yeo SJ, Chin PL. Robot-assisted total knee arthroplasty accurately restores the joint line and mechanical axis. A prospective randomised study. J Arthroplasty. 2014;29:23732377.

6. Yamamura M, Nakamura N, Miki H, Nishii T, Sugano N. Cement Removal from the Femur Using the ROBODOC® System in Revision Total Hip Arthroplasty. Adv Orthop. 2013;2013:347-358.

7. Sood A, Jeong W, Peabody JO, Hemal AK, Menon M. Robot-assisted radical prostatectomy: inching toward gold standard. Urol Clin North Am. 2014;41:473-484.

8. Taylor GW1, Jayne DG. Robotic applications in abdominal surgery: their limitations and future developments. Int J Med Robot. 2007;3:39.

9. Liu H, Lawrie TA, Lu D, Song H, Wang L, Shi G. Robot-assisted surgery in gynaecology. Cochrane Database Syst Rev. 2014. doi: 10.1002/14651858.CD011422. 